\title{
Calculating Web Impact Factor for University Library Websites in Sri Lanka
}

\author{
Kokila H. Ramanayake ${ }^{1}$, Chen Xianqiao ${ }^{2}$, Shi Bing ${ }^{3}$
}

\begin{abstract}
This paper aims to explore a Revised Web Impact Factor (RWIF) for university library websites in Sri Lanka and the correlations between RWIF with external backlink and page count. The RWIFs were calculated by dividing external backlink counts by the number of pages found in Yahoo, and Google search engines and SEO CHAT application tool for each university library website at a given point in time. Collectively, 6,850 average web pages and 630 average external backlinks were found from studied university library websites. University of Moratuwa library website received the highest RWIF of 0.4415 , which indicates that the number of externally linked pages to www.lib.mrt.ac.lk is much higher than that of other universities. It was found that external backlink count and RWIF were correlated and associated and it shown that there was very less difference between the external backlink count and RWIF. Research results found that there was no much association or closeness between page count and RWIF. The main factors that can raised RWIF of a university library website were linking of websites to their affiliate universities, university libraries, international websites, internet guides and search engines and making appropriate information resources, such as getting access to the university's electronic journals, library resources, the news, information from conferences available and easily accessible, and usable for its users audiences and as a result the website will receive more external backlinks. The findings of the study will guide to the librarians to evaluate the strength of their online presence of their library websites and plan to improve their status on the web.
\end{abstract}

Keywords: Library Websites, Impact Factor, Webometrics, Link Analysis, Website Evaluation, Usability

\footnotetext{
${ }^{1}$ Senior Assistant Librarian, University of Ruhuna, Email: kramanayaka@gmail.com

(iD) http://orcid.org/0000-0002-6784-1686

${ }^{2}$ The School of Computer Science \& Technology Wuhan University of Technology Hubei, China, Email: chenxa@whut.edu.cn

${ }^{3}$ The School of Computer Science \& Technology Wuhan University of Technology Hubei, China,Email: 744047249@qq.com
} 


\section{Introduction}

Academia and the researchers all over the world have identified the World Wide Web (WWW) as one of the key sources of information for research activities. The websites embedded in WWW provide a public interface for researchers and information seekers around the world a global gateway into the knowledge repositories of academic work. Thus the websites have been identified as an easiest and effective way of publishing academic knowledge (Babu, Jeyshankar \& Rao, 2010). Detlor and Lewis expresses that 'library websites should not only provide as gateways to a varied collection of information resources, but function as sophisticated guidance systems which support users across a wide range of information seeking behaviors, from goal directed search to aimless browsing' (Detlor \& Lewis, 2006). A library website plays an enhanced role compared to its traditional physical library and offers a wide variety of library services such as electronic resource access, online catalogs, virtual information about the library, enabling online feedback and requests, Web 2-.0 services and online reference services for its users. Thus, having an effective website meeting with the needs of all type of users is a necessity for libraries.

Nowadays, library website evaluation has attracted increasing concern amongst librarians because of the library website serves as a key entry to library services. Prospective benefits of an effective website existence include greater research impact and attracting users. Therefore it has been imperative to investigate the measurements of effectiveness of websites where efforts would be taken to study the communication activity that they represent and to build useful evaluation metrics (Vaughan \& Thelwall, 2005). Measuring the impact of library websites is of great significance to researchers because websites are now becoming the major source of information on research and academic activities for the university. The Web Impact Factor (WIF) is considered to provide a website's relative significance and competitive relationship with other websites in the same field or domain. The WIF is one of the most important tools used to measure the quantitative activities of the website and it provides quantitative measure for ranking, evaluating, categorizing, and comparing websites (Idrees, 2015). 


\section{Research Objectives}

The major objective of the research study is to examine the Revised Web Impact Factor (RWIF) of university library websites in Sri Lanka. The other inter-linked objectives are to:

1.Explore the factors that determine the RWIF of a website from an extensive literature survey

2.Identify online web diagnostic tools which can be used to collect quantitative data for identified factors

3.Calculate the RWIF for the university library websites in Sri Lanka; and 4.Calculate the correlation between RWIF with external backlink and page count of university library websites in Sri Lanka

\section{Literature Review}

The term WIF was initiated by Ingwersen in 1998 based on the same pattern as Journal Impact Factor to measure the impact of websites in a particular field of study and was considered to provide a website's relative importance and competitive relationship to other websites in the same field or domain (Noruzi, 2006). Furthermore Noruzi (2006) expressed that a greater WIF would indicate more visibility and greater success of the website, both nationwide and internationally, making the site more reliable and popular. Ingwersen (1998) proposed the WIF was a method of measuring the influence of websites on each other, and of analyzing links between institutions. Jeyshankar and Badu (2009) expressed that the WIF was part of the methodology of webometrics and recognized as a new measure of the extent to which a site was linked to by other sites. Further, it was similar to a citation count in the print environment. Furthermore, the authors posed that the higher the WIF, the higher the perceived reputation of the website and it provided a quantitative tool for ranking, evaluating, categorizing, and comparing websites. Thelwall (2002) remarked that the WIF could be used directly to measure impact on the website, or indirectly to provide a metric that may associate with important offline phenomena.

Thomas and Willett (2000) conducted a webometric analysis of the departments of library and information science websites in United Kingdom universities by using the link and URL features in AltaVista advanced search for the purpose of obtaining counts of the numbers of links to another site. 
With regards of the Smith and Thelwall study, they used both AltaVista and AllTheWeb search engines and the academic crawler to calculate the WIF for Australasian universities websites (Smith \& Thelwall, 2002). Li et al. (2003) calculated the WIFs for computer science department's websites in United Kingdom from the link data collected both from AltaVista search engine and the special academic crawler and Thelwall, Tang and Price (2003) used advanced query features in the AltaVista search engine to carry out a webometric study of universities of 16 European countries. An and Qiu (2004) calculated the WIF of 42 Chinese engineering journal websites using Lycos search engine to perform external link counts and Qiu, Chen and Wang (2004) studied the backlink counts, external backlink counts and the WIFs for Chinese university websites by choosing the AltaVista and AllTheWeb search engines to collect necessary data. Vaughan and Wu (2004) did a study on WIF for websites of China's top 100 information technology companies using major commercial search engines namely, Google, AltaVista, AllTheWeb, and MSN. Mukhopadhyay (2005) conducted studies on the WIF for SAARC countries academic and research institutions in India with getting required data from Alltheweb, AltaVista, and Hotbot search engines and Smith (2005) examined the counts for conventional citations and links to a sample of library and information science e-journal websites, and calculated WIFs for the e-journals using AltaVista search engine. Later, Onyancha and Ocholla (2007) explored the WIFs for selected websites of Kenyan and South African universities using the SocSciBot computer software and the SocSciBot toolkit and AltaVista and Google, two top ranked search engines.

Elgohary (2008) investigated the WIF of 99 Arab universities representing 20 Arab countries using AltaVista search engine. Using the AltaVista search engine, Nwagwu and Agarin (2008) collected data on web links in 30 Nigerian university websites to study the pattern and frequency of outlinks and inlinks. Aminpour et al., (2009) conducted a study of overall and absolute WIFs for Iranian universities of medical sciences and Jeyshankar and Babu (2009) studied the websites of 45 universities in Tamil Nadu and calculated the simple, self-link and external WIFs for these websites by using AltaVista search engine for collect data. Babu, Jeyshankar and Rao (2010) examined websites of the 40 central universities in India by getting help from 
AltaVista search engine and calculated the simple, external, self-link and revised WIFs for the subject websites. The study conducted by Jalal, Biswas and Mukhopadhyay (2010) analyzed the web presence and visibility of websites of selected Asian countries to find out the WIF using popular search engines like AltaVista, Google, Yahoo and MSN. Islam and Alam (2011) calculated the overall and absolute WIFs of 44 private university websites in Bangladesh by examining the number of web pages and link pages by using AltaVista search engine. Jalal (2013) investigated the relationship among top 10 world universities, top 10 Asian universities and top 10 Indian universities by considering inlinks and outlinks count using Yahoo search engine. Elhouri, Elkabani and Hamandi (2014) conducted an analytical study of 24 Lebanon university websites by using Yahoo, AltaVista and Google search engines, and Majestic SEO tool to find the WIF and Web Indicators of Science, Innovation and Research (WISER) and the correlation between rankings of WIF and WISER. Furthermore, in this study, they implemented an automated ranking and recommendation system for Lebanon university websites. Chakravarty and Wasan (2015) calculated the WIF and RWIF of top 10 library websites of higher education institutes in India by desiring Google search engine and correlated these two formulas. Their results shown that the positive and strong relationship between WIF and RWIF were very less difference between the two ranking methods. Khan and Idrees (2015) explored the WIFs for websites of Pakistani universities using open site explorer service namely, Developer Shed and two commercial search engines namely, Google and Bing. Furthermore they endeavoured to rank the top 5 websites of Pakistan universities by considering four different website ranking systems and compared the WIFs of university websites of other developing countries as well.

In summary, the literatures point out the fact that the importance of assessing web presence of websites and there are no studies that analysis the web presence of websites in Sri Lankan university libraries. As a contribution to addressing this need, this study was aimed to examine the RWIF of university library websites in Sri Lanka. 


\section{Methodology}

The current research belongs to webometric studies and is intended to calculate the RWIF for the university library websites in Sri Lanka, and the correlation between factors. The study was conducted in March 2016. The universities chosen for the study are the 15 government universities in Sri Lanka (Universities and Higher Educational Institutions, 2016). The URLs of these university library websites were identified by visiting the parent university websites and verify that these URLs were in separate domains for these library website and subject directory indexed. In here, the authors examined that only 9 university libraries were qualified with the above conditions. So this study examined the websites of 9 university libraries in Sri Lanka which are listed in Table 1, together with their corresponding URLs.

\section{Table 1: Website URLs of university libraries in Sri Lanka}

\begin{tabular}{|c|c|c|}
\hline Ref & Library & Home URL \\
\hline$\overline{\mathrm{U} 1}$ & Sabaragamuwa University of Sri Lanka & http://www.lib.sab.ac.lk \\
\hline $\mathrm{U} 2$ & The Open University of Sri Lanka & http://lib.ou.ac.lk \\
\hline U3 & University of Colombo & $\begin{array}{l}\text { http://www.lib.cmb.ac.1 } \\
\text { k }\end{array}$ \\
\hline $\mathrm{U} 4$ & Unive & http://www.lib.jfn.ac.lk \\
\hline U5 & University of Moratuwa & http://www.lib.mrt.ac.lk \\
\hline U6 & University of Peradeniya & http://www.lib.pdn.ac.lk \\
\hline $\mathrm{U} 7$ & University of Ruhuna & http://www.lib.ruh.ac.lk \\
\hline $\mathrm{U} 8$ & University of Sri Jayewardenepura & http://lib.sjp.ac.lk \\
\hline U9 & $\begin{array}{l}\text { University of the Visual \& Performing } \\
\text { Arts }\end{array}$ & http://lib.vpa.ac.lk \\
\hline
\end{tabular}

\section{Calculating Revised Web Impact Factor (RWIF)}

The WIF is generally defined as the ratio between the number of links received and the total number of web pages of a particular website (Idrees, 2015). There are three types of link namely, outlinks or external links which are HTML code on the website which allows site visitors to access other websites, inlinks or backlinks which are hyperlinks on someone else's website that direct visitors to your site, and self-links which are navigational links used in a website to direct users from one page to another page within 
the site (Noruzi, 2006). Therefore, according to the Noruzi, there are three types of WIF including Overall WIF, Inlink (Revised) WIF, and Self-link WIF (Noruzi, 2006).

The formula for calculating Overall WIF is:

Overall Web Impact Factor $=\frac{X+Y+Z}{P}$

where, the variable $\mathrm{X}$ represents the number of outlinks, $\mathrm{Y}$ represents the total backlink, $\mathrm{Z}$ represents the total self-link count and $\mathrm{P}$ represents the number of web pages published on the websites which are indexed by a search engine.

However, Noruzi's research shown that self-links for the website under evaluation can provide ambiguous results, as the number of self-links can be manipulated by different means by site owners. For example, in some cases, self-link counts increase because of email addresses associated with websites, which is identified by the search engine as links to that specific domain. On the other hand, self-links are an important percentage of the links that a website receives; therefore, the author expressed that self-links are less meaningful than inlinks because self-links within a website can be created for navigation purposes rather than for endorsing the contents (Noruzi, 2006). In addition, the importance of inlinks is threefold (Vaughan \& Thelwall, 2005) namely;

- more visibility on the web and potentially more traffic to the site

- better coverage by search engines, and

- higher ranking in search results

The RWIF is the result of excluding self-links for a website, thus establishing an analogous impact factor (Idrees, 2015). So in this study, the authors calculated the RWIF for websites in Sri Lankan university libraries as shown below:

Revised Web Impact Factor $(R W I F)=\frac{X}{Y}$

where, the variable $X$ represents the inlinks (external backlinks) to the website and $Y$ represents the number of web pages published on the websites which are indexed by a search engine. 


\section{Calculating relationship between external backlinks and RWIF}

The relationship between external backlinks and RWIF can be presented through the correlation coefficient. The correlation coefficient explains the strength and direction of linear relationship between two variables. Whereas the coefficient of determination represents the percent of the data closest to the line of best fit. Correlation is always between -1.0 and +1.0 and if it is positive, there has a positive relationship. Otherwise, the relationship is negative (Madhusudhan \& Prakash, 2013) (Elhouri, Elkabani \& Hamandi, 2014). In the present study, the authors decided to use the Spearman's Rank Correlation to find the relationship between external backlinks and RWIF of university library websites in Sri Lanka. According to this method,

Correlation Coefficient $(r)=\frac{N \sum X Y-\left(\sum X\right) *\left(\sum Y\right)}{\operatorname{sqrt}\left(\left[N \sum X^{2}-\left(\sum X\right)^{2}\right]\left[N \sum Y^{2}-\left(\sum Y\right)^{2}\right]\right)}$

where, the variable $\mathrm{X}$ represents the external backlinks count of the university library website, variable Y represents the RWIF of each university library website, $\Sigma$ is the Algebraic sum and $\mathrm{N}$ is the number of libraries considered.

\section{Calculating relationship between page count and $R$ WIF}

The relationship between page count and RWIF also can be presented through the correlation coefficient using the formula (3). In formula (3), the variable $X$ represents the total page count of the university library website, variable Y represents the RWIF of each university library website, $\Sigma$ is the Algebraic sum and $\mathrm{N}$ is the number of libraries considered.

\section{Selection of search engine}

When carrying out a WIF study, it is necessary to select a suitable search engines and other related software tools that will count the number of pages in the website studied, and the number of pages linking to the website and it should have a large database, covering as much of the web as possible (Smith, 2005). Furthermore, it should be enormous, cover more hyperlinks with advanced search facilities to count links possessed by the websites (Chakravarty \& Wasan, 2015). The WIF studies conducted by Ingwersen (1998), Thomas and Willett (2000), Smith and Thelwall (2002), Li et al. (2003), Thelwall, Tang and Price (2003), Qiu, Chen and Wang (2004), Vaughan and Wu (2004), Mukhopadhyay (2005), Smith (2005), Onyancha 
and Ocholla (2007), Elgohary (2008), Nwagwu and Agarin (2008), Aminpour et al. (2009), Jeyshankar and Babu (2009), Babu, Jeyshankar and Rao (2010), Jaa, Biswas and Mukhopadhyay (2010), Shekofteh et al. (2010), Islam and Alam (2011), Jati (2011), Eccles, Thelwall and Mever (2012), Jalal (2013) and Madhusudhan and Prakash (2013) had used the advanced search features of the AltaVista or Yahoo search engine. The WIF studies accomplished by Vaughan and Wu (2004), Onyancha and Ocholla (2007), Jaa, Biswas and Mukhopadhyay (2010), Arif and Ismail (2013), Madhusudhan and Prakash (2013), Chakravarty and Wasan (2015) and Khan and Idrees (2015) have been used Google search engine to count the links. The studies accomplished by Onyancha and Ocholla (2007), Arif and Ismail (2013) and Khan and Idrees (2015) have been used SocSciBot computer software and the SocSciBot toolkit, Majestic search engine optimization (SEO) service, Developer Shed software in addition with the search engines for gather data.

Jalal, Biswas and Mukhopadhyay (2010) and Parrish (2016) mentioned that AltaVista was once the most popular search engine, and for a while ranked closely behind Google and Yahoo but from 2004, AltaVista was owned by Yahoo and AltaVista's home page was redirected to Yahoo's main page with powered from the Yahoo search index. In present study, therefore, the authors decided to choose Yahoo, Google search engines and SEO CHAT application to collect data, i.e., number of web pages and number of external backlinks. The reason for using two search engines and a software tools is to cross-verify the results because the indexing techniques applied by search engines are different in terms of technology and approach (Lee, 2009).

\section{Data Collection Strategy}

The required data were collected in March 2016 using search engines namely; Yahoo and Google and Majestic Search Engine Optimization (SEO) service tool in order to limit errors associated with frequent website updates. In each search engine, there were some specific search keywords assigned by the search engines to retrieve the required information from the Web. These specific search keywords along with search syntax have been presented in the following table (Table 2). 
Table 2: Search Syntax

\begin{tabular}{|c|c|c|}
\hline $\begin{array}{l}\text { Search } \\
\text { engine }\end{array}$ & $\begin{array}{l}\text { Inlinks (external backlinks) to the } \\
\text { website }\end{array}$ & Number of web pages \\
\hline $\begin{array}{l}\text { Google } \\
\text { Yahoo }\end{array}$ & $\begin{array}{l}\text { link:www.lib.ruh.ac.lk -site:ruh.ac.lk } \\
\text { (link: www.lib.ruh.ac.lk/ AND NOT } \\
\text { (link: www.lib.ruh.ac.lk/ AND url: } \\
\text { www.lib.ruh.ac.lk/)) OR (link: } \\
\text { www.lib.ruh.ac.lk/ AND NOT (url: } \\
\text { www.lib.ruh.ac.lk/ AND link: } \\
\text { www.lib.ruh.ac.lk/)) }\end{array}$ & site:www.lib.ruh.ac.lk \\
\hline $\begin{array}{l}\text { Majestic } \\
\text { SEO }\end{array}$ & $\begin{array}{l}\text { "External Backlink" parameter from } \\
\text { the "FreshIndex" }\end{array}$ & $\begin{array}{l}\text { value of indexed URL } \\
\text { parameter }\end{array}$ \\
\hline
\end{tabular}

\section{Data Analysis and Results}

\section{Calculating Revised Web Impact Factor}

The page count and external backlink count for selected university library websites in Sri Lanka are listed in Table 3.

Table 3: Page Count and External Backlink Count External Backlink Count Page Count

\begin{tabular}{|c|c|c|c|c|c|c|c|c|}
\hline Library & Google & Yahoo & Majestic & Average & Google & Yahoo & Majestic & Average \\
\hline Name & & & SEO & & & & SEO & \\
\hline U1 & 25 & 19 & 22 & 22.00 & 276 & 260 & 251 & 262.33 \\
\hline U2 & 40 & 44 & 36 & 40.00 & 3330 & 3270 & 3390 & 3330.00 \\
\hline U3 & 126 & 145 & 106 & 125.67 & 922 & 1310 & 534 & 922.00 \\
\hline U4 & 20 & 3 & 8 & 10.33 & 115 & 32 & 74 & 73.67 \\
\hline U5 & 149 & 176 & 122 & 149.00 & 336 & 381 & 291 & 336.00 \\
\hline U6 & 110 & 80 & 140 & 110.00 & 290 & 390 & 406 & 362.00 \\
\hline U7 & 61 & 51 & 66 & 59.33 & 1410 & 1194 & 979 & 1194.33 \\
\hline U8 & 112 & 31 & 192 & 111.67 & 314.5 & 255 & 374 & 314.5 \\
\hline U9 & 2 & 2 & 1 & 1.67 & 55 & 55 & 54 & 54.67 \\
\hline
\end{tabular}


As it is indicated in Table 3, the library website in the Open University of Sri Lanka has the largest average page count, followed by the library websites in University of Ruhuna and University of Colombo. As for the average external backlink count, the library website in University of Moratuwa has the highest count, followed by the library websites in University of Colombo and University of Sri Jayewardenepura.

Table 4: Revised Web Impact Factors for University Library Websites

\begin{tabular}{ccccc}
\hline $\begin{array}{c}\text { Library } \\
\text { Name }\end{array}$ & $\begin{array}{c}\text { Google } \\
\text { RWIF }\end{array}$ & $\begin{array}{c}\text { Yahoo } \\
\text { RWIF }\end{array}$ & $\begin{array}{c}\text { Majestic } \\
\text { RWIF }\end{array}$ & $\begin{array}{c}\text { Average } \\
\text { RWIF }\end{array}$ \\
\hline U1 & 0.0906 & 0.0731 & 0.0876 & 0.0838 \\
U2 & 0.0120 & 0.0135 & 0.0106 & 0.0120 \\
U3 & 0.1367 & 0.1107 & 0.1985 & 0.1486 \\
U4 & 0.1739 & 0.0938 & 0.1081 & 0.1253 \\
U5 & 0.4435 & 0.4619 & 0.4192 & 0.4415 \\
U6 & 0.3793 & 0.2051 & 0.3448 & 0.3098 \\
U7 & 0.0433 & 0.0427 & 0.0674 & 0.0511 \\
U8 & 0.3561 & 0.1216 & 0.5134 & 0.3304 \\
U9 & 0.0364 & 0.0364 & 0.0185 & 0.0304
\end{tabular}

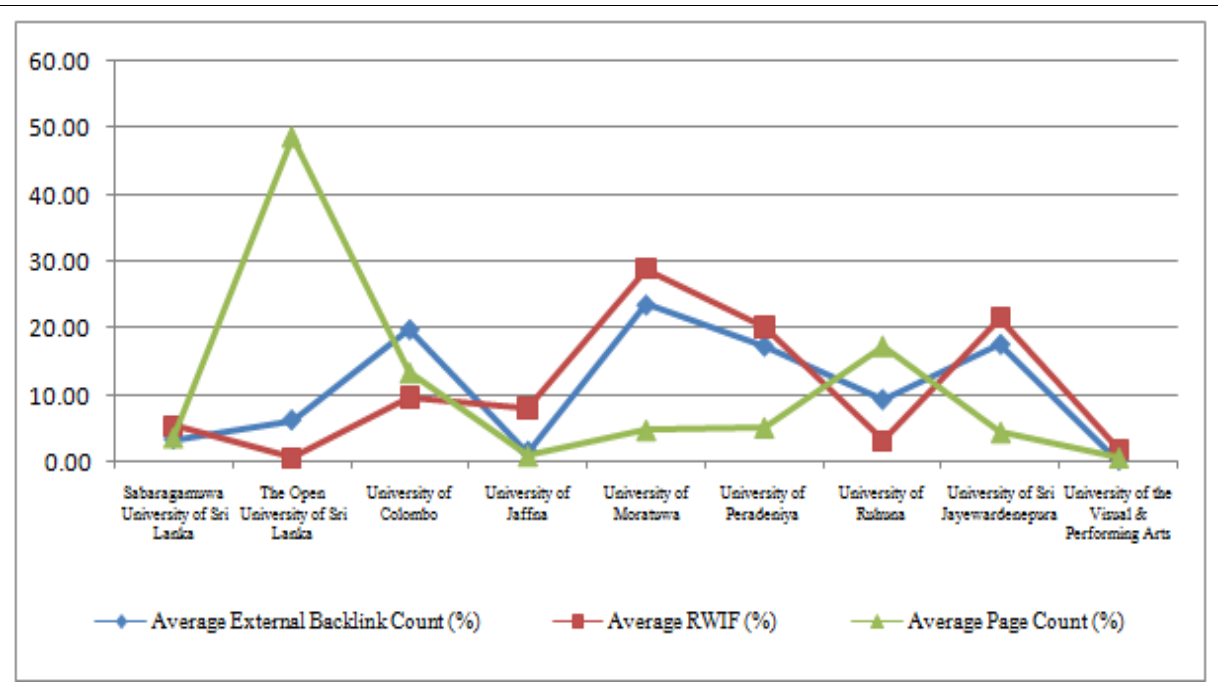

Figure 1 : Distribution of average percentage values of RWIF, external backlink count and page count of University Library Websites in Sri Lanka 
The RWIF for library websites in Sri Lankan universities were listed in table 4. For Google RWIF, University of Moratuwa library website has the highest RWIF followed by the library websites in University of Peradeniya and University of Sri Jayewardenepura. For Yahoo RWIF, University of Moratuwa library website again has the highest RWIF followed by the library websites in University of Peradeniya and University of Sri Jayewardenepura. For Majestic WIF, University of Sri Jayewardenepura library website has the highest RWIF followed by the library websites in University of Moratuwa and University of Peradeniya. For the Average RWIF, University of Moratuwa library website also has the highest RWIF followed by the library websites in University of Sri Jayewardenepura and University of Peradeniya. Figure I shows the distribution of the average values of RWIF, external backlink count and page count of university library websites in Sri Lanka in terms of percentage. It reflects useful information on the study's findings about the current impact, visibility and usability levels in university library websites in Sri Lanka.

\section{Relationship between external backlink and RWIF}

The following is the calculation of the correlation coefficient ( $r$ ) between external backlink (X) and RWIF (Y) based on the data collected using the formula (3).

Here, $\mathrm{N}=9, \sum \mathrm{XY}=162.1318, \sum \mathrm{x}=629.67, \sum \mathrm{Y}=1.5329, \sum \mathrm{x} 2=68276.56$, $\sum \mathrm{Y} 2=0.4485$

$r$

$$
\begin{gathered}
=\frac{9 * 162.1318-(629.67 * 1.5329)}{\operatorname{sqrt}([9 * 68276.56-629.67 * 629.67][9 * 0.4485-1.5329 * 1.5329])} \\
r=\frac{1459.096-965.2211}{\operatorname{sqrt}(218004.7 * 1.6867)} \\
r=\frac{493.8751}{606.393} \\
r=+0.8144
\end{gathered}
$$

Thus, value of correlation coefficient (r) which has positive value shows positive relationship between external backlink and RWIF which implied that there is much association or closeness between external backlink and RWIF. In other words, there is very less difference and closeness between external backlink and RWIF. 


\section{Relationship between page count and RWIF}

The calculation of the correlation coefficient ( $\mathrm{r}$ ) between page count $(\mathrm{X})$ and RWIF (Y) based on the data collected using the formula (3) is shown below. Here, $\mathrm{N}=9, \sum \mathrm{XY}=635.3999, \sum \mathrm{x}=6849.50, \sum \mathrm{Y}=1.5329, \sum \mathrm{x} 2=$ $13785500.36, \sum \mathrm{Y} 2=0.4485$

$$
\begin{gathered}
r \\
=\frac{9 * 635.3999-(6849.50 * 1.5329)}{\operatorname{sqrt}([9 * 13785500.36-6849.50 * 6849.50][9 * 0.4485-1.5329 * 1.5329])} \\
r=\frac{5718.5995-10499.4007}{\operatorname{sqrt}(77153853.0 * 1.6867)} \\
r=\frac{-4780.8}{11408.71} \\
r=-0.41905
\end{gathered}
$$

The calculated correlation between page count and RWIF was negative, i.e. 0.41905 , which means that the relation between two methods is inversely related. It reveals that there is not much association or closeness between page count and RWIF.

\section{Discussion}

The WIF analysis method presents a methodology for evaluating "global visibility" and impact of websites, as well as their competitive relations to other websites and benefits from universal recognition as one of numerous measures of ranking websites. The WIF can be regarded a sensible tool to measure the relative visibility of a company, organization, or country on the web. However, it must be noted that the WIF is not the only indicator of the use, visibility, and popularity of a web site (Noruzi, 2006) (Shekofteh, et al. 2010).

The number of links received by a website shows number of visitors it attracts giving an indication of impact on the web compared to the other web sources (Aminpour et al., 2009). The present study calculated and compared the number of web pages, external backlinks, RWIF and also the correlation coefficients between RWIF with external backlink count and page count for Sri Lankan university library with active exclusive websites. The external backlink count and RWIF are significantly correlated with Sri Lankan university library websites. On this backdrop, the main factor that can raise 
RWIF of a university library website is to make appropriate information resources easily accessible and usable for its users. Electronic publishing and distributing scientific materials via a library website will attract more audiences resulting more external backlinks and higher RWIF. Furthermore, establishing new websites and web logs under the main website and linking them to their affiliate universities, university libraries, international websites, internet guides and search engines can be very effective in enhancing the rate of web links and WIF of library websites, if such links are to follow various scientific motives such as getting access to the university's electronic journals, library resources, the news, information from conferences, etc. Apart of that, the web designs and the links between pages should be functionally corrected enabling the search engines easily access and index the newest materials uploaded to the websites which helps the users easily find their favourable information in the shortest possible time (Aminpour et al., 2009).

As to the realistic contribution, the study proposed the measurement item to evaluate the impact factor of library websites. This measurement item will be able to help librarians to improve the visibility and usability of library websites. Moreover, the present study is evidence based; therefore, the methodology used in this study might be helpful for other libraries to examine the WIF to compare with other library websites and identify visibility and usability problem areas of their respective websites. The framework used in this study makes it suitable for libraries having limited budgets to ensure that they develop more effective library website with maximum information. There are 16 government universities in Sri Lanka (Universities and Higher Educational Institutions, 2016). The university libraries chosen for this study were only 9 because other 7 university library website urls were not exist in separate domains during the study period of March, 2016. Therefore, the current study has revealed an issue in finding the page counts and external backlink counts of these 7 library websites from the search engines. Although web search engines are not perfectly suitable for measuring the web impact factor, it is still a very applicable tool. Most obviously, several researchers had noted that, current search engine technology cannot be relied upon to provide comprehensive, reliable data (Ingweren, 1998). So the variability of results of the same search engine over 
different times is the main limitation of the study. However, the data was collected on two rounds to overcome this limitation.

\section{Conclusion}

WIF is becoming a more reliable indicator worldwide to measure the scientific utility of websites (Idrees, 2015). From the study, it can be concluded that an analytical study of RWIF of 9 university library websites in Sri Lanka was presented using several search engines and other web tools. Collectively, 6,850 average web pages and 630 average external backlinks were found for these 9 university library websites and University of Moratuwa library website has the highest average RWIF with 0.4415 . There is positive correlation i.e. +0.8144 shows positive relationship between external backlink and RWIF for the case of Sri Lankan university library websites which implied that there is much association or closeness between external backlink and RWIF. And the result shows that there is not direct relationship between page count and RWIF. Therefore, volume of external backlink count is an important indicator for influencing RWIF of library websites.

This study has some important lessons for librarians of Sri Lankan university libraries regarding the library websites. Librarians need to be aware of different measures of effectiveness and visibility of websites and they have been keen to have high link counts by promoting their websites through other external websites. Further research is needed to gain a better understanding to find reasons for the limited number external backlink counts related with each university library websites, and further research may be necessary to compare RWIF with other leading university library websites in the Asian region. Also further research is needed to investigate the web presence and usability of websites whether they effect with WIFs. In the next phase of this research, the authors plan to continue working with design and implement an automated ranking and recommendation system for Sri Lankan university library websites according to different ranking approaches.

Acknowledgement :The authors would like to express their sincere gratitude to all those who have significantly contributed towards the completion of this article 


\section{References}

Aminpour, F., Kabiri, P., Othroj, Z., \& Keshtkar, A. A. (2009). Webometric analysis of Iranian universities of medical sciences. Scientometrics, 80(1), 253-264.

An, L., Qiu, J. (2004). Research on the Relationships between Chinese Journal Impact Factors and External Web Link Counts and Web Impact Factors. The Journal of Academic Librarianship, 30(3), 199204.

Arif, A., Ismail, N. A. (2013). Web Impact Factor for Malaysian Public Universities. International Journal of Future Computer and Communication, 2(3), 151-154.

Babu, B. R., Jeyshankar, R., \& Rao, P. N. (2010). Websites of Central Universities in India: A Webometric Analysis. Journal of Library \& Information Technology, 30(4), 33-43.

Battleson, B., Booth, A., \&Weintrop, J. (2001). Usability testing of an academic library website: A case study. The Journal of Academic Librarianship, 27(3), 188-198.

Chakravarty, R., \& Wasan, S. (2015). Webometric Analysis of Library Websites of Higher Educational Institutes (HEIs) of India: A Study through Google Search Engine. Journal of Library \& Information Technology, 35(5), 325-329.

Detlor, B., Lewis, V. (2006). Academic Library Web Sites: Current Practice and Future Directions. The Journal of Academic Librarianship, 32(3) , 251-258.

Eccles, K. E., Thelwall, M., \& Meyer, E. T. (2012). Measuring the web impact of digitised scholarly resources. Journal of Documentation, 68(4), 512-526.

Elgohary, A. (2008). Arab universities on the web: a webometric study. The Electronic Library, 26(3), 374-386.

Elhouri, W., Elkabani, I., \& Hamandi, L. (2014). A Webometric Analysis of Some Universities in Lebanon. 21st Century Academic Forum Conference Proceedings, (pp. 153-168). Berkeley. 
Idrees, A. K. (2015). Calculating Web impact factor for university websites of Pakistan. The Electronic Library, 33(5), 883-895.

Ingwersen, P. (1998). The calculation of web impact factors. Journal of Documentation, 54(2), 236-243.

Islam, A., Alam, S. (2011). Webometric study of private universities in Bangladesh. Malaysian Journal of Library \& Information Science, 16(2), 115-126.

Jalal, S. K. (2013). A Comparative Weblink Analysis among Top Indian, Asian and World universities. Journal of Library \& Information Technology, 33(2), 131-140.

Jalal, S. K., Biswas, S. C., \& Mukhopadhyay, P. (2010). Web Presence of Selected Asian Countries: A Webometric Study. Collnet Journal of Scientometrics and Information Management, 4(2), 1-12.

Jati, H. (2011). Web Impact Factor: a Webometric Approach for Indonesian Universities. International Conference on Informatics for Development (pp. 74-77). ICID 2011.

Jeyshankar, R., Babu, R. (2009). Websites of universities in Tamil Nadu: a webometric study. Annals of Library and Information Studies, 56, 69-79.

Lee, J. (2009). Patent No. US 2009/0234807 A1. United States.

Li, X. (2003). A review of the development and application of the Web impact factor. Online Information Review, 27(6), 407-417.

Li, X., Thelwall, M., Musgrove, P., \& Wilkinson, D. (2003). The relationship between the WIFs or inlinks of Computer Science Departments in UK and their RAE ratings or research productivities in 2001. Scientometrics, 57(2), 239-255.

Madhusudhan, M., Prakash, S. (2013). Websites of Indian Institutes of Technology: A webometric Study. International Journal of Library and Information Studies, 3(4), 93-107. 
Mukhopadhyay. (2005). Measuring Web Impact Factors: A Webometric Study based on the Analysis of Hyperlinks. Proceedings of National Seminar on Information Support for Rural Development (pp. 1-12). IASLIC.

Noruzi, A. (2006). The web impact factor: a critical review. The Electronic Library, 24(4), 490-500.

Nwagwu, Williams E., Agarin, Omoverere (2008). "Nigerian University Websites: A Webometric Analysis" Webology, 5(4), vailable at: http://www.webology.org/2008/v5n4/a62.html

Onyancha, O. B., Ocholla, D. N. (2007). The Performance of South African and Kenyan Universities on the World Wide Web: a Web Link Analysis. International Journal of Scientometrics, Informetrics and Bibliometrics, 11(1).

Parrish, K. (2016). Yahoo! Finally Shutting AltaVista Down on July 8. Retrieved 4 14, 2016, from tom's guide: http://www.tomsguide.com/us/Search-Engine-Yahoo-AltaVista-Dotcom-Google,news-17130.html

Qiu, J., Chen, J., \& Wang, Z. (2004). An analysis of backlink counts and Web Impact Factors for Chines university websites. Scientometrics, 60(3), 463-473.

Shekofteh, M., Shahbodaghi, A., Sajjadi, S., \& Jambarsang, S. (2010). Investigating Web impact factors of type 1, type 2 and type 3 medical universities in Iran. Journal of Paramedical Sciences, 1(3), 34-41.

Shukla, A., Vanlalfeli. (2014). Webometric Development in Web Impact Factor Studies: A Literary Review. Journal of Advancements in Library Sciences, 1(3), 28-36.

Smith, A. G. (2005). Citations and Links as a Measure of Effectiveness of Online LIS Journals. IFLA Journal, 35(1), 76-84.

Smith, A., Thelwall, M. (2002). Web Impact Factors for Australasian universities. Scientometrics, 54(3), 363-380. 
Snyder, H., Rosenbaum, H. (1999). Can search engines be used as tools for web-link analysis? A critical view. Journal of Documentation, 55(4), 375-384.

Thelwall, M. (2000). Web impact factors and search engine coverage. Journal of Documentation, 56(2), 185-189.

Thelwall, M. (2002). A comparison of sources of links for academic Web impact factor calculations. Journal of Documentation, 58(1), 66-78.

Thelwall, M., Tang, R., \& Price, L. (2003). Linguistic patterns of academic Web use in Western Europe. Scientometrics, 56(3), 417-432.

Thomas, O., Willett, P. (2000). Webometric analysis of departments of librarianship and information science. Journal of Information Science, 26(6), 421-428.

Universities and Higher Educational Institutions. (2016). Retrieved 3 20, 2016, from University Grants Commission - Sri Lanka: http://www.ugc.ac.lk/en/universities-and-institutes/universities.html

Vaughan, L., Thelwall, M. (2005). A modeling approach to uncover hyperlink patterns: the case of Canadian universities. Information Processing and Management, 41(2), 347-359.

Vaughan, L., Wu, G. (2004). Links to commercial websites as a source of business information. Scientometrics, 60(3), 487-496. 